\title{
Synthesis of ferroceramics for electromagnetic shock waves generators by vacuum aerosol deposition method
}

\author{
O.L.Rezinkin ${ }^{1}$, M.M.Rezinkina ${ }^{2}$, O.G.Gryb ${ }^{1}$ \\ ${ }^{1}$ National Technical University "Kharkiv Polytechnic of Institute", \\ 21 Frunze Str., 61102 Kharkiv, Ukraine \\ ${ }^{2}$ State Institution "Institute of Technical Problems of Magnetism, \\ National Academy of Sciences of Ukraine, 19 Industrial Str., 61106 \\ Kharkiv, Ukraine
}

Received May 24, 2016

\begin{abstract}
Experimental bench and regimes of aerosol deposition at room temperature in vacuum of the fine grained ferroelectric layers with thickness of several hundred microns (the grains' size is less than $1 \mu \mathrm{m}$ ) and general formula $\mathrm{BaO}-\mathrm{SrO}-\mathrm{TiO}_{2}$ have been described. The results of experimental investigations of electrical physical characteristics of the obtained samples have been presented. It is shown that electric breakdown strength of the obtained ferroelectric layers exceeds in 1.4-2.5 times the electric breakdown strength of the similar samples made by the hot synthesis technology.

Keywords: ferroelectric ceramics, room temperature impact consolidation, electric strength, non-linear electrical properties, pulse generators of currents and voltages.
\end{abstract}

Описан экспериментальный стенд и технологические режимы аэрозольного напыления при комнатной температуре на металлических подложках-электродах в вакууме слоев мелкозернистой сегнетокерамики (размер зерен меньше, чем 1 мкм) с общей формулой $\mathrm{BaO}-\mathrm{SrO}-\mathrm{TiO}_{2}$ толщиной в несколько сотен микрон. Приведены результаты экспериментальных исследований электрофизических характеристик полученных образцов. Показано, что электрическая прочность полученных таким образом слоев сегнетокерамики в 1,4-2,5 раза превышает электрическую прочность аналогичных образцов, изготовленных с помощью технологии горячего синтеза.

Синтез сегнетокераміки для електромагнітних генераторів ударних хвиль за допомогою вакуумного аерозольного напилювання. О.Л.Резинкін, М.М.Резинкіна, О.Г.Гриб.

Описано експериментальний стенд та технологічні режими аерозольного напилювання при кімнатній температурі на металевих підкладках-електродах у вакуумі шарів дрібнозернистої сегнетокераміки (розмір зерен менший за 1 мкм) із загальною формулою BaO-SrO$\mathrm{TiO}_{2}$ товщиною у кілька сотень мікрон. Наведено результати експериментальних досліджень електрофізичних характеристик отриманих зразків. Показано, що електрична міцність отриманих таким чином шарів сегнетокераміки в 1,4-2,5 рази перевищує електричну міцність аналогічних зразків, виготовлених за допомогою технології гарячого синтезу.

\section{Introduction}

Development of advanced methods for dielectric synthesis opens the new possibilities for manufacture of dielectric materials with improved non-linear electrical properties. This allows usage of the nonlinear electrical processes that occur in the dielectric medium upon electromagnetic fields influence for creation of the new types of compact and reliable solid state 
pulsed power generators of currents and voltages. Such generators can be used for testing of electronic devices on electromagnetic compatibility, in experimental studies of plasma physics, in laser and radar technique, in communications and other areas of the modern science and technology.

One of the advanced methods of highpower electromagnetic impulses with a short rise time producing is the shock waves generation in a media with the nonlinear electric or magnetic parameters [1, 2]. Besides, usage as a working medium of the materials with the nonlinear dielectric permeability [3] has advantages compared with the electromagnetic pulses generation in the nonlinear ferromagnetic medium [4]. Impedance of forming lines (FL) on the ferroelectrics is much lower than at usage the non-linear magnetic materials. Ceramics based on the solid solutions of ferroelectrics may be used as a FL working medium [5]. The traditional method of ferroelectric ceramic manufacturing is the high-temperature synthesis [6].

One of the most important parameters that determine the applicability of the ferroelectric to sharpen of voltage and current impulses is the relaxation transition time from one polarized state to another, which differs from the original state by the level and direction of the electrical induction vector field. The smaller dimensions of domains formed by homogeneous spontaneous polarization zones in the ferroelectric, the shorter duration of polarization transition appears. So it is quite important to get the ferroelectric with extremely fine crystalline structure. Obtaining of the domains of nanometer dimensions is possible if feedstock from which the ceramics is synthesized has the nanodisperse structure. However, simple grinding of the raw material, being itself a complex scientific and technical problem does not certainly result in the fine grain structure of the polycrystalline ferroelectric. Three-component system BaO$\mathrm{SrO}-\mathrm{TiO}_{2}$ is widely used for obtaining of the ferroelectric with the high nonlinear characteristics. At such a ceramics manufacturing by the conventional method of the high-temperature synthesis, which includes burning in the temperature range of $1200-1400^{\circ} \mathrm{C}$, active growth of the crystals and, as a consequence, reduction of the high frequency properties of obtained ferroelectrics take place.

One of the most advanced methods of ferroelectric synthesis is the technology of the room temperature impact consolidation (RTIC) of ferroelectric ceramic powders in vacuum [7-9]. This technology opens up the new direction in the field of nanostructured composite materials synthesis. It is currently used mainly for coatings production in the microelectronics areas, MEMS and optics. It seems promising to spread this technology in the area of electrical engineering and, in particular, in the high-voltage impulse technology. To generate the electromagnetic shock waves of megawatt and gigawatt power, it is necessary to create a forming line filled with the nonlinear working media operating at the high voltages. To provide the electric strength of the forming line for voltages of the units tens of kilovolts, the thickness of its working medium should not be less than a few millimeters for currently known nonlinear dielectrics.

Production of relatively thick ferroelectric samples without cracks and other heterogeneities that reduce their electric strength is a complex and time-consuming task. Therefore, physical and mathematical modeling of the high-voltage shock waves that occur in such lines are quite important for choice of the lines configuration. The mathematical modeling [10-12] provides recommendations on the required levels of nonlinearity of the working medium dielectric permeability as well as its geometrical configuration.

The mathematical modeling of electromagnetic processes at the propagation of electromagnetic waves with a rise time of the order of units - tens of nanoseconds should be formulated taking into account the final time of the working medium polarization setting. For such a solution the so-called modified magnetic vector potential may be used [10-12]. This approach provides significant reduction of the number of the solved equations, which is very important in 3D approach. Such a problem may be solved also using the equivalent electrical circuits with nonlinear parameters [3, 13].

The aim of this work is to develop technique for manufacturing of the relatively thick ferroelectric samples as a working body for impulse generators using the method of vacuum aerosol deposition at the room temperature. 


\section{Experimental bench for ferroelectric samples obtaining by the vacuum aerosol deposition}

An installation shown in Fig. 1 was created for a series of experimental researches in the area of manufacturing of the new electrical materials with the non-linear physical properties.

Vacuum pump VP allows to evacuate chamber $D C$ up to pressure $P_{D C}=0.5-$ $1.5 \mathrm{kPa}$. Accelerating gas from high-pressure cylinder $G C$ fills elastic receiver $R e$ at the atmospheric pressure. The accelerating gas gets to aerosol generator $A C$ from the receiver through rotameter Ro. Gas pressure in the aerosol generator is maintained within the range of $P_{A C}=50-70 \mathrm{kPa}$ using the rotameter $R o$ and jet nozzle $J$. The aerosol generator has a container filled with powder milled ferroelectric. The accelerating gas in the aerosol generator is mixed with the powder and supplied to the input of nozzle $N$. The pressure drop at inlet and outlet of the nozzle leads to the aerosol acceleration in its cavity.

The mean free path of the accelerating gas molecules is comparable with cross-sectional size of the nozzle and three orders of magnitude higher than the ceramic particles average diameter, so the process of particle acceleration in the nozzle should be considered from the point of view of the molecular-kinetic theory of gases. The ceramic particles acquire near sonic speed as a result of acceleration at the nozzle exit. The ceramic particles collision with substrate causes their destruction. Under formation of the new chemical bonds, appearing instead of the broken ones in the process of particles destruction, couplings of the crystal structure fragments with the substrate and the adjacent fragments happen. This explains the high adhesion of the synthesized ceramics to the substrate, as well as its high density and strength. Not all of the ceramic particles are destroyed and react with the substrate and with the neighboring particles. At collision of the ceramic particles moving at angle to the substrate surface, their destruction becomes less probable. The interaction of such particles with the substrate causes cleaning of its surface from contaminants, that promotes the joining other particles to the substrate. Unreacted powder is carried away by the flow of spent accelerating gas and it is delayed by electrostatic precipitator EC. Collisions experienced by the particles of the unreacted pow-

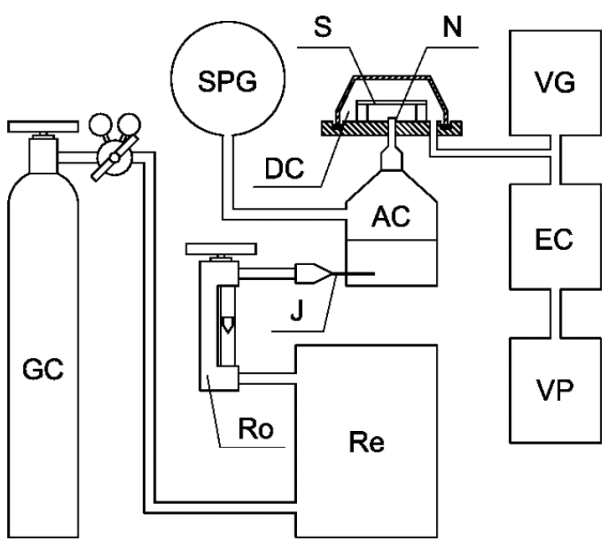

Fig. 1. Installation for synthesis of non-linear dielectrics. $A C$ is aerosol generator, $D C$ is vacuum chamber, $V P$ is vacuum pump, $N$ is nozzle, $S$ is substrate, $V G$ is vacuum gauge 13BT3-003, $S P G$ is standard pressure gage $B O, G C$ is high-pressure cylinder with accelerating gas, $R e$ is receiver, $R o$ is rotameter RC-3A, $J$ is jet nozzle, $E C$ is electrostatic precipitator.

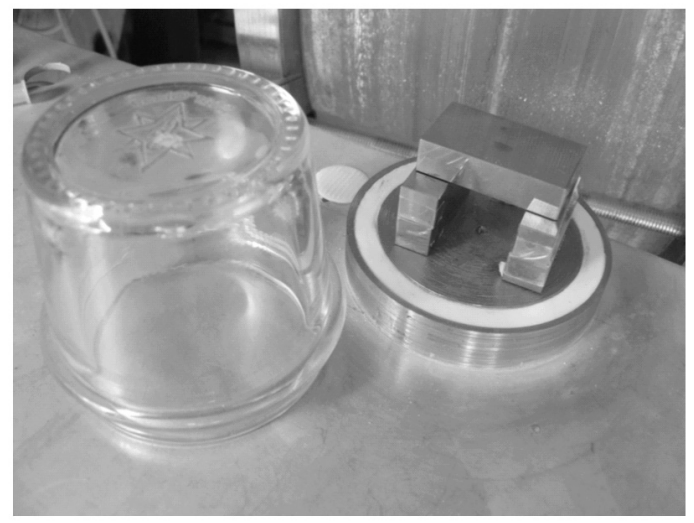

Fig. 2. Working chamber of the experimental installation to form coating by aerosol deposition method.

der during the flight in the installation channels lead to accumulation of the internal stress in them, which has a positive effect on their reactivity at reusing.

A transparent chamber of small volume attached to the vacuum unit was used as a deposition camber (see Fig. 2). Such a setup permits to simplify the procedure of substrate replacing after completion of the next experiment, and also allows observing of the deposition process.

Low pressure (about 1-2 kPa) was supported in the deposition chamber with the help of a rotary vacuum pump during the process of coating deposition. A nozzle with the circular cross-section of $0.5 \mathrm{~mm}^{2}$ and copper substrate has been used. 


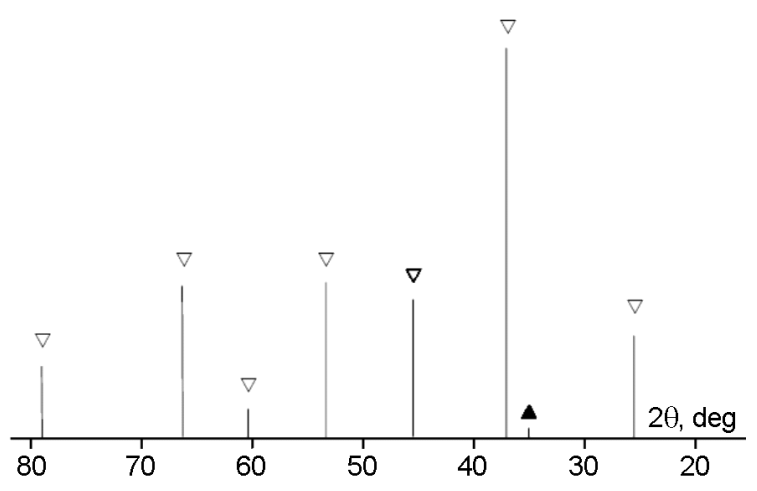

Fig. 3. XRD of the ferroceramic material. $\nabla-\mathrm{Ba}_{0,75} \mathrm{Sr}_{0,25} \mathrm{Ti}_{0,95} \mathrm{Zr}_{0,05} \mathrm{O}_{2}, \boldsymbol{\Delta}-\mathrm{ZrO}_{2}$.

The spray was created by mixing the powder particles consisting of the barium strontium titanate $\left(\mathrm{BaSrTiO}_{3}\right)$, doped by zirconium, lead and other additives with dehydrated nitrogen into an aerosol-generating chamber with cylindrical shape. To ensure the particles selection, whirling gas flow, formed during entrance of the carrier gas flow in the chamber input, was used. For this, the flow was directed tangentially to the circle, which is concentric with the circle of the aerosol generating chamber crosssection. The powder was poured onto the chamber bottom, from where the particles were picked up by the whirling flow. Carrier gas $\left(\mathrm{N}_{2}\right)$ was fed into the aerosol-generating chamber from the receiver. The carrier gas flow rate was regulated by a rotameter, and for the most of experiments was set at $0.6 \mathrm{l} / \mathrm{min}$.

In the experiments the ferroelectric powders with different initial dispersion degree (mode of the particles diameter $\mathrm{D}[1,0]$ was from $40 \mu \mathrm{m}$ to $50 \mathrm{~nm}$ ) were used. Control of the particles diameter was carried out by optical and electron microscopy. Poorly controlled aggregation arises inevitably at the powder aerosol generator filling process. Additional material selection by the particles size was carried directly into the aerosol generator. It was observed that collisions with the substrate of the particles with rather big and middle sizes even for a long time (up to half an hour) lead to formation of a very thin coating layer. Moreover, such a coating is easily disrupted, and conduction current arises in it even at application of the low voltage. Unlike the described case, the result of the synthesis using ferroelectric with the smaller particles was the dense samples with deposited layers thicknesses from 20 to $250 \mu \mathrm{m}$ (depo-

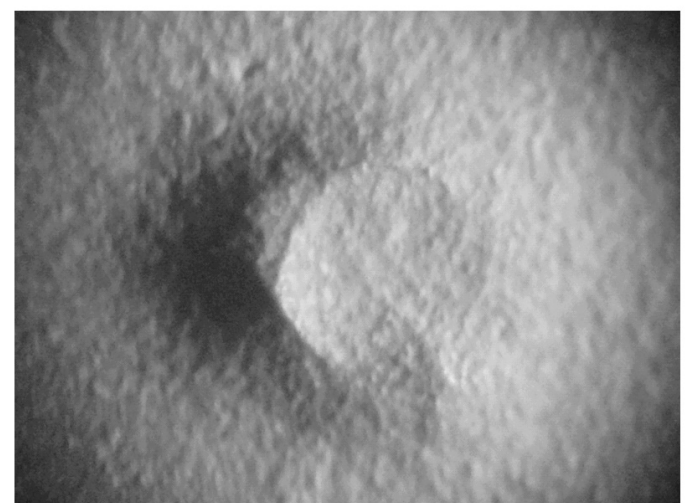

Fig. 4. Sample of ferroceramic coating, deposited on copper substrate by vacuum aerosol deposition at the room temperature.

sition time was $10-20 \mathrm{~min})$. To enhance the effect of the powder smaller particles being picked up by the carrier gas swirl into the aerosol-generating chamber, devices for creation of so-called "boiling layer" (BL) have been designed. Continuous mixing of the particles on the surface of the powder, filling the chamber happens in such a "boiling layer". It turned out that the most efficient method of the $\mathrm{BL}$ creating is influence of the powder in the aerosol chamber by the low-frequency acoustic waves $(100-500 \mathrm{~Hz})$, for which an electrodynamic acoustic radiator was placed in the aerosol chamber. Effectiveness of the BL produced by the acoustic radiator, its optimal location and its operating frequency depend substantially on the aerosol chamber designs and were selected experimentally.

Fig. 3 shows the results of X-ray analysis of barium strontium titanate powder, doped by zirconium $\mathrm{Ba}_{0.75} \mathrm{Sr}_{0.25} \mathrm{Ti}_{0.95} \mathrm{Zr}_{0.05} \mathrm{O}_{2}$, which confirm the selected crystallographic phase composition of the ferroelectric and the absence of its significant pollution by the side technological crystalline impurities. The phase composition of the synthesized dielectric was controlled in the process of deposition. The results of this research have shown the initial phase structure preservation at the coating synthesis. Complete $\mathrm{X}$-rays analysis spectra contain also specific peaks, which correspond to copper (substrate material).

As a result of the described installation working, a dense layer of the ferroelectric ceramics is formed on the substrate surface. Unlike the thermal, ionic, magnetron, vacuum-arc and other deposition methods, this technology allows getting quickly a very thick coating layer. For example, the rate 


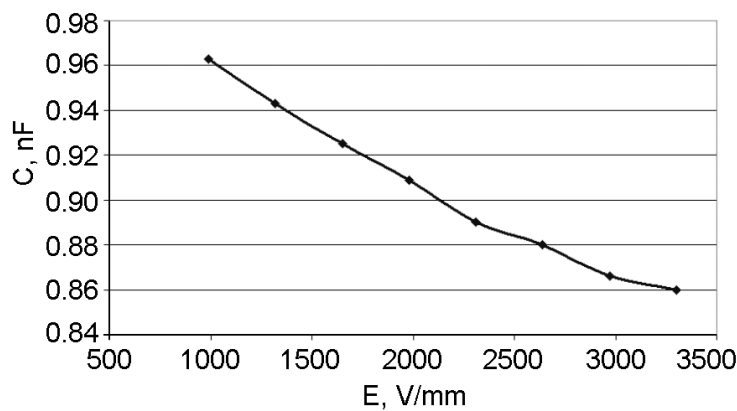

Fig. 5. Dependence of $\mathrm{Ba}_{0,77} \mathrm{Sr}_{0.23} \mathrm{TiO}_{3}$ sample synthesized by aerosol deposition method on electric field strength.

of deposition of the ceramics, which is solid solution of barium titanate and strontiumdoped zirconia on copper substrate was 5$35 \mu \mathrm{m} / \mathrm{min}$. Fig. 5 presents a sample of such ferroelectric, which deposited layer thickness equals to $250 \mu \mathrm{m}$. Duration of the sample synthesis was $10 \mathrm{~min}$ at the accelerating gas flow rate equals to $0.6 \mathrm{l} / \mathrm{min}$. Nitrogen having the water content not higher than $0.25 \%$ was used as the applied accelerating gas. A nozzle with the circular cross section having outlet diameter of $0.5 \mathrm{~mm}$ was used. The distance between the nozzle's outlet and the substrate was $6 \mathrm{~mm}$. The initial material for the ferroelectric synthesis was got by the cryogenic dispersing of ceramic in the gas-dynamic flow.

Grinding technology used for the powder preparation plays an essential role for the ceramic efficient synthesis on the substrate surface. The deposition process happens intensely if the accumulated mechanical stress in the powder particles is sufficient for their ease destruction by a stroke. The gasdynamic cryogenic grinding was used in this case, which enables obtaining the powder with the required level of mechanical stress in its particles. The used substrate material was electrical copper without any surface pre-treatment. The probability of destruction and reaction of the collided ceramic particles moving obliquely to the surface of the substrate is smaller than for the particles colliding with the substrate at angles close to the direct one, and not all of them form the ferroelectric coating. At interaction of these particles with the substrate, its surface is cleansed from mechanical and chemical contaminants that contributes the adherence the other substrate particles. Mechanical strength of the ferroelectric synthesized from the powder at the room temperature, practically coincides with the mechanical strength of the samples obtained from the same material by conventional hot fusion at temperature of $1270^{\circ} \mathrm{C}$ using isostatic pressing of the samples at pressure of $900 \mathrm{~kg} / \mathrm{cm}^{2}$.

Possibility to carry out the synthesis of ferroelectric at the room temperature is a significant advantage of the vacuum aerosol deposition. The temperatures required for the hot fusion lead not only to grain growth in the ceramic and corresponding worsening of its high frequency electrical properties. The traditional technology usage, which includes the ceramic samples burning, makes practically impossible creation of the complex composite structures with internal metal electrodes and separate ferroelectric and ferromagnetic elements. To such structures, in particular, izoimpedance mediums, metamaterials, multilayer compositions belong [14].

It was found that in the process of the ceramics synthesis a valley of $50 \mu \mathrm{m}$ thickness is formed on the sample reverse side on the surface of copper foil that is opposite to the ferroelectric layer. Depth of this valley depends not only on the ceramic thickness but also on the deposition process parameters (accelerating gas consumption, powder concentration in the aerosol, ceramics particles velocity, etc.). This phenomenon demonstrates significance of adhesion forces of the ceramics to the substrate, the great ceramics mechanical strength, as well as presence of the mechanical stress in the synthesized ferroceramics layer. The mechanical stresses presence in the ferroelectric can influence the character of its polarization process. Annealing at the temperatures much lower than the temperature of the hot synthesis may be used to reduce or eliminate the mechanical stress of the deposited ceramic layer. According to [11], short time heating of the deposited coating to temperature of $600^{\circ} \mathrm{C}$ is enough for stress elimination and reaching of the dielectric permeability and piezoelectric coefficient in ferroelectric $\mathrm{Pb}\left[\mathrm{Zr}_{x} \mathrm{Ti}_{1-x}\right] \mathrm{O}_{3}$ of the values corresponding of the samples obtained by the classical technology.

\section{Experimental determination of electrical parameters of the ferroelectric ceramic samples obtained by vacuum aerosol deposition}

Electrical strength is an important electrical physical characteristic at practical 
usage of the ferroelectric materials in the high-voltage impulse technology.

Descending branch of dielectric permittivity dependence on electric field strength is used at the ferroelectrics application as an active dielectric of the high voltage forming lines for solution of a number of problems of the power electric and magnetic fields technique. The most complete saturation of polarization and, consequently, the greatest decrease in the dielectric permeability levels, necessary for the efficient operation of powerful sharpeners and electromagnetic pulse generators, are observed in electric fields, the level of which strength is close to the breakdown electric strength of the working medium. The experimental determination of the breakdown electric strength of the ceramic samples with thickness of deposited layer of $50 \mu \mathrm{m}$ (see Fig. 4), has shown that this characteristic is much larger than for the ceramic samples manufactured by the high-temperature synthesis. At the measuring of the electrical breakdown strength of the deposited ferroelectric samples in the capacitor oil medium, the breakdown values $E_{b r}=17-$ $25 \mathrm{MV} / \mathrm{m}$ were obtained. The $E_{b r}$ levels depend on the deposition regimes. These values are 1.4-2.5 times higher than the electrical breakdown strength of the ferroelectric samples of the same structure obtained by the classical technology.

The Sawyer-Tower scheme $[15,16]$ was used in the experimental study of electrical parameters of the samples obtained with the help of the aerosol deposition method. Voltages with different frequencies and voltage impulses with the amplitudes up to $2.5 \mathrm{kV}$ were applied to the samples. The sample was placed in a system of two planar electrodes, one of which was formed by the copper substrate and the other was coated on the ferroelectric surface as a layer of silver deposited from the conductive lacquer AMEPOX MICROELECTRONIC ELECTON 40 AC after its drying in air at the room temperature.

Fig. 5 shows a typical plot of the capacity of got by the vacuum aerosol deposition of ferroelectric sample based on barium strontium titanate, on the strength of the applied electric field with frequency of $1 \mathrm{GHz}$.

\section{Conclusions}

The method of vacuum aerosol deposition at the room temperature allows obtaining of ferroelectric $\mathrm{Ba}_{x} \mathrm{Sr}_{1-x} \mathrm{Ti}_{y} \mathrm{Zr}_{1-y} \mathrm{O}_{3}$ dense layers with thickness of several hundred microns on the not prepared copper surface. The density and mechanical strength of the ceramics synthesized by this method are similar to these characteristics, measured on the samples obtained by the conventional hot synthesis. The layers of ceramics, applied by the aerosol deposition method, are mechanically stressed. The breakdown electric strength of the deposited layers is 1.42.5 times greater than for the samples of the same structure obtained by the hot synthesis technology. The achieved speed of ferroceramic powder deposition allows to use of the synthesized coatings not only in the areas of technology involving their microscopic sizes (microelectronics, MEMS, photonics), but also in the power and electrical engineering, as well as in the highvoltage impulse technology.

\section{References}

1. I.G.Kataev, Electromagnetic Shock Wave, Soviet Radio, Moscow (1963) [in Russian].

2. J.K.Bogatyrev, Izvestiya VUZov. Radiofizika, 8, 1171 (1965).

3. G.Branch, P.W.Smith, J.Phys. D:Appl.Phys., 29, 217 (1996).

4. O.Vendik, L.Ter-Maritosyan, I.Mironenko, Ferroelectrics, 144, 34 (1993).

5. T.N.Verbitskaya, Variconds, Gosenergoizdat, Moscow (1958) [in Russian].

6. G.V.Lisachuk, L.O.Bilostotska, Yu.D.Trusova et al., Functional Materials, 22, 547 (2015).

7. J.Akedo, M.Lebedev, Jpn.J.Appl.Phys., 38, 5397 (1999).

8. J.Akedo, J.Thermal Spray Techn., 17, 181 (2008).

9. J.Akedo, M.Lebedev, Materia, 41, 459 (2002).

10. M.M.Rezinkina, O.L.Rezinkin, Techn. Phys., 56, 406 (2011).

11. M.M.Rezinkina, Elektrichestvo, 8, 50 (2003).

12. M.M.Rezinkina, Techn. Phys., 52, 1407 (2007).

13. M.Rezinkina, E.Bydianskaya, A.Shcherba, The Environmentalist, 27, 417 (2007).

14. Y.K.Fetisov, A.A.Bush, K.E.Kamentsev et al., IEEE Sensors J., 6, 935 (2006).

15. C.B.Sawyer, C.H.Tower, Phys.Rev., 35, 269 (1930).

16. O.L.Rezinkin, A.-K.Axelsson, V.V.Vytrishko, Instrum. Experim. Techn., 53, 755 (2010). 